\title{
Two preparations for the study of the isolated rabbit oviduct
}

\author{
H. J. Leese, P. G. Humpherson and Kate S. Jeffries \\ Department of Biology, University of York, York Y01 5DD, U.K.
}

\begin{abstract}
Summary. When rabbit oviducts were slit open along their length, cut into small pieces, and incubated in Krebs-Ringer-bicarbonate medium, the tissue slices took up $\mathrm{O}_{2}$ at a steady rate for $40 \mathrm{~min}$, retained approximately $70 \%$ of their adenine nucleotides, and were suitable for metabolic studies of the oviduct. In a second preparation, oxygenated Krebs-Ringer-bicarbonate medium was recirculated at 700 $\mu \mathrm{l} / \mathrm{min}$ through the lumen of the whole oviduct, severed of its blood supply, while the serosal surface was bathed in a similar medium. The preparation took up $\mathrm{O}_{2}$, maintained a steady potential difference across its mucosal and serosal surfaces, and transported 2-deoxy $\mathrm{D}$-glucose selectively for at least $40 \mathrm{~min}$. In oviducts taken from rabbits injected 3 days previously with hCG, there was $>4$-fold increase in the initial transmural potential difference.
\end{abstract}

\section{Introduction}

Most of our knowledge on the oviducal secretions is derived from experiments in which the oviducts of intact animals have been cannulated, and the secretions collected over long periods of time (Hamner \& Fox, 1969; Hamner, 1973; Brackett \& Mastroianni, 1974). Understanding of the biochemical mechanisms underlying secretory or absorptive phenomena in other mammalian epithelial tissues, such as the small intestine, gall bladder and pancreas, has come from the use of in-vitro preparations. We now report the development of two such preparations of the rabbit oviduct.

\section{Preparation 1: slit oviduct tissue slices}

\section{Methods and Results}

Early attempts at developing an in-vitro preparation of the rabbit oviduct involved the use of (a) thin rings of whole oviduct, (b) thin slices of whole tissue cut from oviducts which had been slit open along their length after removal from the rabbit, and (c) scrapings of the mucosal lining of the oviduct (the endosalpinx). The preparations from non-pregnant does were incubated for $10 \mathrm{~min}$ in Krebs-Ringer-bicarbonate medium, $\mathrm{pH} 7.4$, containing $118 \mathrm{mM}-\mathrm{NaCl}, 25$ mM-NaHCO $, 4.74 \mathrm{mM}-\mathrm{KCl}, 1.19 \mathrm{mM}_{3}-\mathrm{MgSO}_{4}, 1.17 \mathrm{~mm}-\mathrm{KH}_{2} \mathrm{PO}_{4}$, and $1.7 \mathrm{mM}-\mathrm{CaCl}_{2}$, and oxygen uptake $\left(\mathrm{QO}_{2}\right)$ was measured in a Clark electrode (Rank Bros, Cambridge). The whole rings of oviduct gave very low $Q \mathrm{O}_{2}$ values, but the quantity of endosalpinx scrapings obtainable was insufficient to give reproducible results. However, the slit tissue slices of preampulla, ampulla and isthmus gave $Q \mathrm{O}_{2}$ values, stable for $30 \mathrm{~min}$, of $4.84 \pm 0.10(n=4), 4.6 \pm 0.59(n$ $=9)$ and $3.4 \pm 0.51(n=10) \mu \mathrm{l} / \mathrm{mg}$ dry wt/h. As a further criterion of viability the tissues 
were deproteinized with $0.6 \mathrm{M}-\mathrm{HClO}_{4}$, the supernatants were neutralized with $5 \mathrm{M}-\mathrm{KOH}$ and analysed, for ATP by the method of Lamprecht \& Trautschold (1974) and ADP and AMP by the method of Adam (1963). The dry weight : wet weight ratio was $0.25 \pm 0.017$ for ampulla slices $(n=15)$ and $0.27 \pm 0.013(n=18)$ for isthmus slices. Using these values, the concentrations (mM) of ATP, ADP and AMP within the tissue water of fresh slices of ampulla were $2.6,1.7$ and 1.3 respectively, and in fresh slices of isthmus were $1.9,1.5$ and $1.4 \mathrm{~mm}$ respectively. The adenine nucleotide content declined only slightly over a 30-min incubation period (Table 1).

Table 1. The ATP, ADP and AMP content of tissue slices from the rabbit oviduct after various times of incubation

\begin{tabular}{lcccc}
\hline & & \multicolumn{3}{c}{ Adenine nucleotide $(\mu \mathrm{mol} / \mathrm{g}$ dry wt) } \\
\cline { 3 - 5 } Tissue & $\begin{array}{c}\text { Time of incubation } \\
(\mathrm{min})\end{array}$ & ATP & ADP & AMP \\
\hline Ampulla & 0 & $7.76 \pm 0.87(7)$ & $5.06 \pm 0.54(9)$ & $3.87 \pm 0.53(9)$ \\
& 12 & $6.26 \pm 0.50(4)$ & $4.79 \pm 1.11(4)$ & $3.70 \pm 0.96(4)$ \\
& 30 & $5.33 \pm 0.49(8)^{*}$ & $2.81 \pm 0.37(8)^{*}$ & $2.94 \pm 0.41(8)$ \\
Isthmus & 0 & $5.09 \pm 0.68(6)$ & $4.15 \pm 0.65(8)$ & $3.74 \pm 0.36(8)$ \\
& 12 & $3.41 \pm 0.56(4)$ & $2.42 \pm 0.63(4)$ & $2.94 \pm 0.24(4)$ \\
& 30 & $4.34 \pm 0.74(7)$ & $2.04 \pm 0.30(7)^{*}$ & $2.21 \pm 0.28(7)^{*}$ \\
\hline
\end{tabular}

Values are mean \pm s.e.m. with no. of determinations in parentheses.

* Indicates significantly different $(P<0.05$ by Student's $t$ test) from the value at $0 \mathrm{~min}$.

\section{Discussion}

As judged by the ability to maintain a steady $Q \mathrm{O}_{2}$, the preparation was viable for at least 40 $\min$. The $Q \mathrm{O}_{2}$ values were of the same order as those reported for rabbit oviduct by Mastroianni, Forrest \& Winternitz (1961). The $Q_{2} \mathrm{O}_{2}$ of the preampulla and ampulla were slightly, but not significantly, higher than that of the isthmus, possibly reflecting the diminished proportion in the isthmus of endosalpinx relative to myosalpinx, the former being more aerobic in its metabolism than the latter (Mastroianni, Winternitz \& Lowi, 1958). The preparations lost approximately $30 \%$ of their adenine nucleotides over a 30 -min period. Loss of nucleotide is characteristic of tissue-slice preparations but the depletion in the present experiments was substantially less than that observed with analogous preparations of liver (Krebs, 1969) and small intestine (Bronk \& Leese, 1973).

We were unable to use this oviduct preparation to study the transport of sugars and amino acids. These nutrients are probably transported across the intact oviduct by facilitated diffusion (Leese \& Jeffries, 1977; Leese, Aldridge \& Jeffries, 1979), a process which may be masked in tissue slices by non-specific diffusion into the myosalpinx, which presumably is not involved in the transport of oviducal fluid constituents in vivo. We think the preparation is more suitable for metabolic studies on the oviduct.

\section{Preparation 2: luminal perfusion of the isolated rabbit oviduct}

The rationale behind the preparation is similar to that adopted by Fisher \& Parsons (1949), who studied the rat small intestine, and involves the recirculation of an oxygenated physiological salt solution through the lumen of the organ at a rate sufficient to satisfy the oxygen and nutritional requirements of the mucosal lining. The serosal surface of the preparation is bathed in a similar recirculating, oxygenated salt solution. A similar approach has been used by Levin \& Edwards (1968) to study the rat uterus. We have assessed the ability of an oviduct preparation to take up 
oxygen, maintain a potential difference between the mucosal and serosal surfaces, and transport sugars and amino acids from the serosal to the mucosal compartment over a 40-min period.

\section{Animals}

New Zealand White rabbits (3-4 kg) were anaesthetized with $35 \mathrm{mg}$ pentobarbitone sodium (Sagatal: May and Baker Ltd, Dagenham, U.K.). In some experiments ovulation was induced by the i.v. injection of 100 i.u. hCG (Pregnyl: Organon Laboratories Ltd, Morden, Surrey, U.K.). Glass cannulae (i.d. $0.6 \mathrm{~mm}$, o.d. $1.2 \mathrm{~mm}$, and i.d. $1 \mathrm{~mm}$, o.d. $2 \mathrm{~mm}$ ) were tied into the uterine and fimbriated ends of the oviduct respectively. The cannula in the isthmus was inserted through an incision in the uterus. The oviduct, with its blood supply still intact, was connected into the mucosal circuit of the apparatus, and the flow of perfusion medium started. For ease of manipulation, the medium was allowed to flow into the oviduct via the isthmus cannula, and out to waste via the cannula in the preampulla. The oviduct was then carefully severed from its blood supply, connective tissue and adhering fat, and the mucosal circuit completed by connecting the preampulla cannula into the return line to the reservoir. The tissue was finally suspended in the serosal medium. The cannulation and setting-up procedure took between 10 and $15 \mathrm{~min}$. It was impossible to remove all the fat adhering to the oviduct, and this could be of importance if the metabolism of nutrients presented to, or appearing in, the serosal compartment was being studied.

\section{Apparatus}

This is shown diagrammatically in Text-fig. 1. The term 'mucosal' refers to the compartment bordering the luminal surface of the oviduct and 'serosal' to that bordering the outer surface of

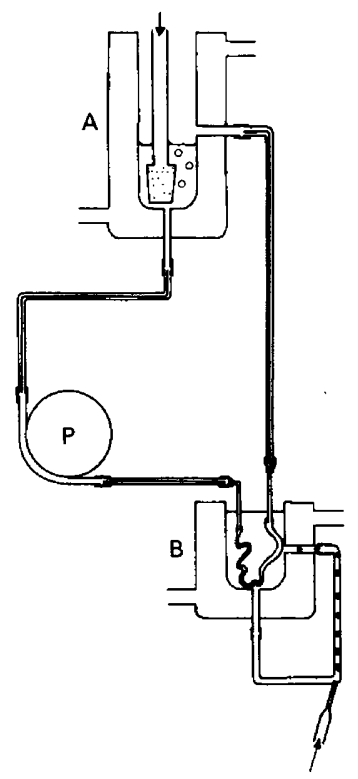

Text-fig. 1. Diagrammatic representation of apparatus for the perfusion of the isolated rabbit oviduct. The mucosal fluid contained in the water-jacketed reservoir (A) at $37^{\circ} \mathrm{C}$ was oxygenated by a stream of moist $95 \%$ oxygen $5 \% \mathrm{CO}_{2}(\mathrm{v} / \mathrm{v})$. The oxygenated fluid was withdrawn at a rate controlled by the peristaltic pump (P) (Gilson Minipuls 2) and entered the oviduct at its uterine end. After leaving the oviduct at the fimbriated end, the fluid was returned via glass tubing to the reservoir. The oviduct was bathed in serosal fluid contained in the water-jacketed vessel, $\mathrm{B}$, at $37^{\circ} \mathrm{C}$, which was also recirculated and oxygenated by a stream of moist $95 \% \mathrm{O}_{2} / 5 \% \mathrm{CO}_{2}$. 
the muscle layers. The medium used for both compartments was Krebs-Ringer-bicarbonate at pH 7.4, and the volume of each compartment was $10 \mathrm{ml}$. Vinyl tubing (i.d. $0.77 \mathrm{~mm}$, o.d. 4.8 $\mathrm{mm}$; Portex Ltd, Hythe, Kent) was used to connect up the various parts of the apparatus but the amount used was kept to a minimum to avoid the loss of oxygen from the perfusion circuit. Preliminary work with dextran blue as marker showed that evaporative losses from the mucosal and serosal fluids were negligible. In some experiments two oxygen electrodes (Rank Bros, Cambridge, U.K.) were incorporated into the mucosal circuit to measure the oxygen tension in the fluid entering and leaving the oviduct. The output from the electrodes was displayed on a twin-channel recorder (Servoscribe: Smiths Industries, Cricklewood, London). In other experiments, the electrical potential difference across the tissue was measured by inserting agar- $\mathrm{KCl}$ bridges into the mucosal and serosal solutions and connecting them to matched calomel electrodes, in turn connected to a high-impedance signal conditioning unit (Type ADM6: Fenlow Electronics, Weybridge, Surrey). The output was again displayed on the Servoscribe recorder.

\section{Oxygen uptake and flow rate measurements}

Precise measurement of the tissue $\mathrm{QO}_{2}$ was difficult for two reasons. Firstly, since it was only feasible to incorporate the oxygen electrodes into the mucosal circuit, it was necessary to prevent bi-directional movements of oxygen between the mucosal and serosal media, as this would give rise to spurious results. This was done by replacing the oxygenated serosal medium with liquid paraffin. Secondly, it was impossible to measure accurately the mass of tissue consuming oxygen. It is likely that the endosalpinx has a higher rate of respiration than the underlying myosalpinx and that the layers of muscle adjacent to the liquid paraffin were probably hypoxic.

However, the oxygen tension measurements enabled $p \mathrm{O}_{2}$ differences to be compared with flow rates of fluid through the oviduct lumen. If the oxygen requirements of the tissue were being satisfied, increases in flow rate (and hence in oxygen delivery per unit time) would be inversely related to the $\mathrm{pO}_{2}$ difference in the medium before and after it entered the oviduct. At flow rates of $700 \mu \mathrm{l} / \mathrm{min}$ and above, this condition was satisfied, and all subsequent experiments were therefore carried out at a flow rate of $700 \mu \mathrm{l} / \mathrm{min}$ for mucosal fluid. At this setting, the $p \mathrm{O}_{2}$ difference between the two electrodes remained steady for $40 \mathrm{~min}$ and was abolished by cyanide addition to the mucosal medium.

\section{Potential difference}

As shown in Text-fig. 2, the potential difference across the oviducts taken from rabbits in oestrus declined from $1.45 \mathrm{mV}$ immediately after setting up the preparation to reach a steady value of just above $1 \mathrm{mV}$ at $20 \mathrm{~min}$. The potential difference was reduced to zero in about $10 \mathrm{~min}$ by the addition of $1 \mathrm{mM}-\mathrm{KCN}$ to the mucosal medium, while $1 \mathrm{mM}$-oubain added to the mucosal and serosal medium caused a reduction of approximately $90 \%$ over the same time period. In oviducts taken from rabbits injected 3 days previously with hCG, there was a large increase in potential difference (Text-fig. 2) and the relative decline was also more marked. However, a steady value was reached and maintained after $30 \mathrm{~min}$.

\section{Sugar transport}

Leese \& Jeffries (1977) showed that the rabbit oviduct perfused through the lumen in vivo could discriminate between D-glucose, and $\mathrm{L}-\left[1-{ }^{14} \mathrm{C}\right]$ glucose infused into the plasma, the D-glucose appearing in the lumen at $\mathbf{1 7}$ times the rate of L-glucose. An attempt was made to mimic this situation in this in-vitro preparation. Preliminary work showed that D-glucose was 


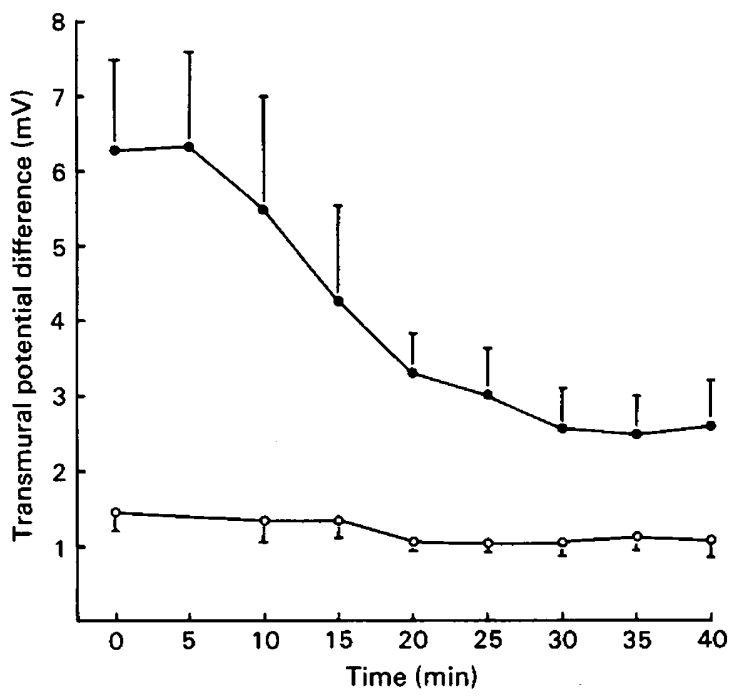

Text-fig. 2. The potential difference across the whole wall of isolated oviducts taken from rabbits at oestrus $(O)$ and 3 days after injection of hCG (O). Values are mean \pm s.e.m. of at least 5 oviducts.

metabolized during its passage across the oviduct wall (possibly by the myosalpinx) and studies were therefore continued with the analogue 2-deoxy D-glucose, which is only weakly metabolized (to 2-deoxy glucose 6-phosphate). The substances 2-deoxy-D-[1- $\left.{ }^{3} \mathrm{H}\right]$ glucose and $\mathrm{L}-\left[1-{ }^{14} \mathrm{C}\right]-$ glucose (sp. act. of each $50 \mathrm{mCi} / \mathrm{mol}$ : Radiochemical Centre, Amersham, Bucks) were added to the serosal medium, each at a concentration of $5 \mathrm{mM}$, and their appearance in the mucosal medium is shown in Text-fig. 3. 2-Deoxy D-glucose was transported at approximately twice the rate of $\mathrm{L}$-glucose.

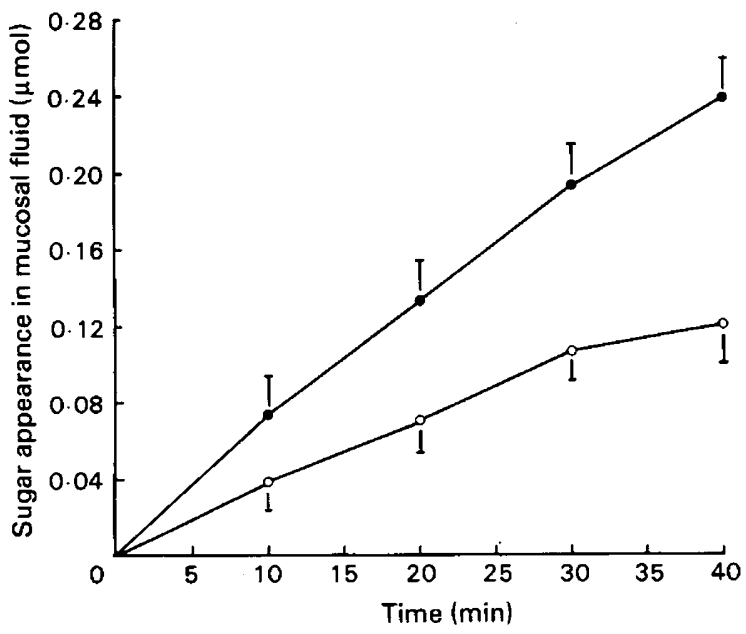

Text-fig. 3. The appearance of 2 deoxy-D-[1- $\left.{ }^{3} \mathrm{H}\right]$ glucose $(0)$ and $L-\left[1-{ }^{14} \mathrm{C}\right] \mathrm{glucose}(\mathrm{O})$ in the mucosal fluid of the in-vitro rabbit oviduct preparation during incubation. Each sugar was added at $5 \mathrm{~mm}$ to the serosal fluid. Values are mean \pm s.e.m. for 5 oviducts. 


\section{Amino acid transport}

Leese et al. (1979) showed that amino acids appeared readily in the lumen of the rabbit oviduct perfused for $4 \mathrm{~h}$ in vivo. A mixture of 20 amino acids in concentrations approximating those in rabbit plasma were therefore added to the serosal compartment, and their appearance in the mucosal compartment was monitored after perfusion for $40 \mathrm{~min}$. The amino acids were detected chemically, using an automatic analyser, as described by Leese et al. (1979). The amounts appearing were very small, and while they could be increased by elevating the initial concentration of amino acids in the serosal compartment, this was considered to be too unphysiological, and the experiments were not pursued.

\section{Discussion}

The in-vitro preparation of the intact rabbit oviduct will take up oxygen, maintain a steady potential difference, and transport 2-deoxy D-glucose selectively for at least $40 \mathrm{~min}$.

As far as we are aware, there is only one other report of the use of an in-vitro preparation to study electrical events and transepithelial fluxes across the rabbit oviduct. This is the pioneering study of Brunton \& Brinster (1971) who showed, using clamped sheets of rabbit ampulla, that the oviduct could maintain a steady transmembrane potential difference (lumen negative as in the present study), and that chloride ions were actively pumped from the serosal to the mucosal solution. The difference in the potential difference recorded by Brunton \& Brinster (1971) (7.4 $\mathrm{mV}$ for the ampulla) and the present result (1.4 $\mathrm{mV}$ for the ampulla and isthmus) could be due to the different tissue preparations, but it is possible, as suggested by Brunton \& Brinster (1971), that different transport processes could be present in different regions of the oviduct. Levin \& Edwards (1968), with a preparation similar to that used here, recorded average values for the isolated rat uterus of $1 \cdot 3,4.3$ and $0.6 \mathrm{mV}$ at dioestrus, pro-oestrus and metoestrus respectively. Levine \& Edwards (1968) also presented persuasive evidence that endometrial rather than myometrial events were largely responsible for the observed potential difference.

The increase in transmural potential difference 3 days after hCG injection (Text-fig. 2) could be due to a number of factors: e.g. an increase in ion pumping activity, a change in the direction of existing ion fluxes or, perhaps most likely, a general 'tightening' of the epithelium at a structural level such that the tissue resistance was increased. The last explanation would correlate with findings that net fluxes of fluid, pyruvate, lactate, glucose and LDH into oviducal fluid are substantially reduced 3 days after ovulation (Riddick, 1975; Leese \& Aldridge, 1979).

The small discrimination between the rates of 2-deoxy D-glucose and L-glucose transport, compared with that between $\mathrm{D}$-glucose and $\mathrm{L}$-glucose in vivo, and the failure to detect the transport of a physiological mixture of amino acids are probably accounted for in part by the need for such compounds to traverse the layers of muscle, which act as barriers to diffusion, before crossing the endosalpinx. The preparation may be well suited to study the consumption of sugars and other substrates presented to the endosalpinx from the mucosal medium, but we were unable to investigate this further.

Raess \& Vincenzi (1980) have recently developed a preparation for perfusion of the isolated rabbit oviduct through its blood supply in order to study ovum transport, and it is possible that this technique could be used to circumvent the problem of diffusion across the muscle layers, and to study the bi-directional fluxes of electrolytes and non-electrolytes across the endosalpinx alone.

We are grateful to $\mathrm{Mr}$ B. Adamson and Mr B. Smith for expert technical help, and the Medical Research Council for a research grant. 


\section{References}

Adam, H. (1963) Adenosine-5-diphosphate and adenosine-5-monophosphate. In Methods of Enzymatic Analysis, 1st edn, pp. 573-577. Ed. H. U. Bergmeyer. Academic Press, New York.

Brackett, B.G. \& Mastroianni, L., Jr (1974) Composition of oviducal fluid. In The Oviduct and its Functions, pp. 133-150. Eds A. D. Johnson \& C. W. Foley. Academic Press, New York.

Bronk, J.R. \& Leese, H.J. (1973) Changes in the adenine nucleotide content of preparations of the rat small intestine in vitro. J. Physiol., Lond. 235, 183-196.

Brunton, W.J. \& Brinster, R.L. (1971) Active chloride transport in the isolated rabbit oviduct. $A m . J$. Physiol. 221, 658-661.

Fisher, R.B. Parsons, D.S. (1949) A preparation of surviving rat small intestine for the study of absorption. J. Physiol., Lond. 110, 36-46.

Hamner, C.E. (1973) Oviducal fluid-composition and physiology. In Handbook of Physiology, Section 7, Vol. II, Part 2, pp. 141-170. Eds R. O. Greep \& E. B. Astwood. Am. Physiol. Soc., Washington, D.C.

Hamner, C.E. F Fox, S.B. (1969) Biochemistry of oviductal secretions. In The Mammalian Oviduct, pp. 333-355. Eds E. S. E. Hafez \& R. J. Blandau. University of Chicago Press.

Krebs, H.A. (1969) Rate control of the tricarboxylic acid cycle. Adv. Enzyme Regulation 8, 335-353.

Lamprecht, W. \& Trautschold, I. (1974) Adenosine5-triphosphate. In Methods of Enzymatic Analysis, 2nd English edn, Vol. 4, pp. 2101-2110. Eds H. U. Bergmeyer \& K. Gawehn. Academic Press, New York.

Leese, H.J. Aldridge, S. (1979) The movement of pyruvate, lactate and lactate dehydrogenase into rabbit oviductal fluid. J. Reprod. Fert. 56, 619-622.

Leese, H.J. \& Jeffries, K.S. (1977) Evidence for the facilitated diffusion of glucose into rabbit oviductal fluid. J. Reprod. Fert. 57, 93-97.

Leese, H.J., Aldridge, S. \& Jeffites, K.S. (1979) The movement of amino acids into rabbit oviductal fluid. J. Reprod. Fert. 56, 623-626.

Levin, R.J. \& Edwards, F. (1968) The transuterine endometrial potential difference, its variation during the oestrous cycle and its relation to uterine secretion. Life Sci. 7, 1019-1036.

Mastrolanni, L., Jr, Winternitz, W.W. \& Lowl, N.P. (1958) The in vitro metabolism of the human endosalpinx. Fert. Steril. 9, 500-509.

Mastrolanni, L., Jr, Forrest, W. \& Winternitz, W.W. (1961) Some metabolic properties of the rabbit oviduct. Proc. Soc. Exp. Biol. Med. 107, 86-88.

Raess, B.U. \& Vincenzi, F.F. (1980) The isolatedperfused rabbit oviduct: a simple experimental preparation. J. Pharm. Meth. 3, 267-273.

Riddick, D.H. (1975) The composition of rabbit oviducal fluid collected continuously throughout gestation. $J$. Reprod. Fert. 43, 563-566.

Received 11 February 1981 